\title{
Masif rotator manşet yaralanmalarında tendon transferi teknikleri ve klinik sonuçlar
}

\author{
Tendon transfer techniques in massive rotator cuff injuries and clinical results
}

\author{
Alper Deveci, Hakan Dur
}

Yüksek Ihtisas Üniversitesi Tıp Fakültesi, Ortopedi ve Travmatoloji Ana Bilim Dalı, Ankara

\begin{abstract}
Masif rotator manşet yırtıkları, tüm manşet yırtıkları içerisinde önemli oranda yer tutmaktadır. Onarılamayan rotator manşet yırtıkları ise masif rotator manşet yırtıkları içerisinde küçük bir oranı temsil eder. Masif rotator manşet yırtığı ile onarılamayan rotator manşet yırtığı terimlerini birbirinden ayırmak gerekir. Masif rotator manşet yırtıklarının çok büyük bir kısmı onarılabilir özelliktedir. Onarılamayan rotator manşet yırtıklarının büyük bölümü ise masif özelliktedir. Onarılamayan rotator manşet yaralanmalarında tendon transferleri çok uzun yıllardır kullanılmaktadır. Temel olarak postero-superior yetmezliklerde, antero-superior yetmezliklerde ve bazı durumlarda reverse omuz artroplastisi ile birlikte kullanılır. Latissimus dorsi, alt trapezius, teres majör, pektoralis majör ve pektoralis minor transferde başlıca kullanılan tendonlardır. Rotator manşet yırtığına bağlı fonksiyonel kayıplar ise temel olarak izole ve kombine olarak ikiye ayrılır. Tendon transferi planlanırken en önemli unsur, bir psödoparalizinin olup olmadığının değerlendirilmesidir. Dolayısıyla, tendon transferi izole aktif fonksiyonun olduğu durumlarda kullanılır. Kombine kayıplar psödoparaliziye neden olduğu için bu durumda tendon transferi yöntemi kullanılmaz.
\end{abstract}

Anahtar sözcükler: rotator manşet yaralanmaları; latissimus dorsi; trapezius kası; tendon transferleri; pektoralis majör; omuz eklemi
Massive rotator cuff tears occupy a significant place among all rotator cuff tears. Irreparable rotator cuff tears represent a small proportion of massive rotator cuff tears. It is necessary to distinguish between the massive rotator cuff tear and irreparable rotator cuff tear. The vast majority of massive rotator cuff tears are repairable. Most of the irreparable rotator cuff tears are massive. Tendon transfers have been used for many years in irreparable rotator cuff injuries. Basically, it is used in postero-superior insufficiency, antero-superior insufficiency and in some cases together with reverse shoulder arthroplasty. The latissimus dorsi, lower trapezius, teres major, pectoralis major, and pectoralis minor are the tendons used in the transfer. Functional losses due to rotator cuff tears are basically divided into isolated and combined. The most important factor when planning tendon transfer is to evaluate whether there is a pseudoparalysis. Therefore, it is used in cases where there is an isolated active function. Since combined functional losses cause pseudoparalysis, tendon transfer method is not used in this case.

Key words: rotator cuff injuries; latissimus dorsi; trapezius muscle; tendon transfers; pectoralis major; shoulder joint

yırtığın büyüklüğü, retraksiyonu, yağlı dejenerasyon ve kas atrofisi nedeniyle primer onarılamadığı durumdur. Onarılamayan yırtıklar genelde masif özellikte olmakla birlikte tek bir tendonu da içerebilir. ${ }^{[3,4]}$ Klinik olarak ağrı ve ileri fonksiyon kaybı görülür. Fonksiyon kaybı çok ileri düzeyde ise psödoparalizi gelişebilmektedir. Omuz eklemi fonksiyonel açıdan elevasyon, internal rotasyon (iR) ve eksternal rotasyon (ER) hareketlerini kombine eder. Burada bahsettiğimiz psödoparalizi temel olarak elevasyonun aktif olarak kaybolmasıdır. Psödoparalitik bir omuzda aktif olarak $45^{\circ}$ 'den fazla

İletişim / Contact: Dr. Alper Deveci • E-posta / E-mail: alperdeveci57@gmail.com

ORCID iD: Alper Deveci, 0000-0001-6216-3030 • Hakan Dur, 000-0001-5535-0911

Geliş / Received: 24 Aralık 2021 • Kabul / Accepted: 2 Şubat 2022 
elevasyon gerçekleşmezken aktif eksternal rotasyonun korunmuş olması olasıdır. ${ }^{[5,6]}$ Radyolojik olarak ise gerçek ön-arka omuz grafisinde humerus başında manşetin bastırma etkisinin kaybolmasıyla birlikte akromiyohumeral mesafenin $<7 \mathrm{~mm}$ altında olduğu, manyetik rezonans incelemede yırtığı içeren manşet kaslarında \%50'nin üzerinde yağlı dejenerasyon, glenoid seviyesine ya da medialine retraksiyon görülebilmektedir. Tedavisiz durumlarda ise ileri dönemlerde manşet artropatisi görülebilmektedir. ${ }^{[6-10]}$

Tendon transferleri manşet yetmezliklerinde temel olarak üç durumda uygulanır; onarılamayan postero-superior manşet yetmezliği, onarılamayan antero-superior manşet yetmezliği ve reverse omuz protezi ameliyatları. $\mathrm{Bu}$ uygulamalarda da kullanılan tendonlar; latissimus dorsi $^{[11]}$, alt trapezius ${ }^{[12]}$, teres majör, pektoralis majör ve pektoralis minördür. ${ }^{[13]}$ Gereksinim duyulan fonksiyon ve yırtık alanına göre bu tendon transferleri tek başlarına ve çeşitli kombinasyonlarla birlikte kullanılabilmektedir.

Rotator manşet yırtığına bağı fonksiyonel kayıplar ise temel olarak izole ve kombine olarak ikiye ayrılır. İzole olanlar da kendi içinde; izole aktif elevasyon kaybı, izole aktif eksternal rotasyon kaybı ve izole aktif internal rotasyon kaybı olarak üçe ayrılır. Kombine olanlar ise; kombine aktif elevasyon ve eksternal rotasyon kaybı, kombine aktif elevasyon ve internal rotasyon kaybı ve her üç fonksiyonun da olmadığı durum olarak üçe ayrılır. Tendon transferleri izole aktif fonksiyonun olduğu durumlarda kullanılır. Kombine kayıplar psödoparaliziye neden olduğu için bu durumda kullanılmaz. ${ }^{[5,14-16]}$

\section{ONARILAMAYAN POSTERO-SUPERIOR ROTATOR MANŞET YIRTIKLARI}

Onarılamayan masif manşet yırtıklarının çoğu bu bölgede görülür. Latissimus dorsi, teres majör, teres majör + latissimus dorsi (L'Episcopo prosedürü) ve alt trapezius bu bölgede transfer için kullanılan tendonlardır.

\section{LATISSIMUS DORSI TRANSFERI}

Latissimus dorsi (LD) kası; humerusa adduksiyon, iç rotasyon ve ekstansiyon yaptırır. Onarılamayan manşet yırtıklarında tendon transferi ile ilgili ilk, en sık ve en fazla çalışma yapılan tendondur. Anatomik olarak triangüler yapıdaki bu kasın geniş bir origosu vardır. Sakrum, posterior iliak krest, T7-L5 spinöz ve 9-12. kaburgalardan başlar. Insersiyosu ise humerus proksimal uçta pektoralis majör ile teres majör arasındaki intertüberküler oluğa gerçekleşir. Torakodorsal sinirden innerve olur. ${ }^{[17,18]}$
Latissimus dorsi transferi Gerber tarafından tanımlanmıştır. ${ }^{[5]}$ Omuz eklemine eksternal rotasyon fonksiyonu ve humerus başı depresyonu sağlayarak, adduksiyon da daha etkili bir deltoid kas gücü oluşturulmasını sağlar. Bu şekilde omuz eklemine öncelikle eksternal rotasyon fonksiyonu kazandırırken işlevsel bir deltoid varlığında abduksiyonu da kolaylaştııır. Dolayısıyla LD transferi için psödoparalizinin olmaması ve aksiller sinirin sağlam olması gerekir. Beraberinde aktif bir deltoid kas gücüne intiyaç vardır. ${ }^{[19]}$ Psödoparalizi terimi günümüzde pasif eklem açıklığı tamken aktif öne elevasyonun $<45^{\circ}$ 'den az olduğu durumdur. ${ }^{[5]}$

Psödoparalizinin olduğu durumda hasta özellikle ileri yaşta ise LD transferinin klinik sonuçlarının kötü olması nedeni ile reverse omuz protezi bir seçenek olabilecektir. Diğer bir durum ise; aktif öne fleksiyonun $90^{\circ}$ 'ye kadar olduğu, $90^{\circ}$ den sonra diğer elin yardımı ile $170^{\circ}$ elevasyonun tamamlandığı ağrıı aktif elevasyon kaybının olduğu yetmezliktir. ${ }^{[15]}$ Eksternal rotasyonun korunduğu fakat ağrılı aktif elevasyon kaybı olan durum latissimus dorsi transferi için en ideal yetmezlik tipidir. Dolayısıyla parsiyel elevasyon kaybının olduğu, omzun hâlen fonksiyonel olduğu, ağrılı ve temel olarak supraspinatusun ağırlıkIı etkilendiği, tek yönde vertikal instabilitenin olduğu durumda ideal bir transferdir. Latissimus dorsi transferi postero-superior manşet yetmezliğinde uygulandığında asıl beklenen fonksiyon aktif öne elevasyondur. ${ }^{[14]}$ Latissimus dorsi transferi kol $90^{\circ}$ adduksiyonda iken eksternal rotasyon etkisi oluşturur. $0^{\circ}$ 'de eksternal rotasyon etkisi zayıftır. Bu sebeple $0^{\circ}$ 'de ve $90^{\circ}$ 'de total eksternal rotasyon kaybı, infraspinatusa ek olarak teres minör yetmezliğinin olduğu durumlarda alt trapezius transferi daha uygun bir seçenektir. ${ }^{[20,21]}$

Latissimus dorsi transferi endikasyonu olan hastaların klinik muayenesinde eksternal rotasyon lag ve droparm testleri pozitiftir. Retrakte yırtık olan supraspinatus ve infraspinatusun glenoid seviyesine (Patte 3 ) ve hatta medialine kadar retrakte olduğu görülebilir. ${ }^{[9]}$ Yine manyetik rezonans görüntüleme (MRG) değerlendirmesinde yağlı dejenerasyon (Goutallier Grade >3) görülebilmektedir. ${ }^{[6,7]}$

Latissimus dorsi transferi öncelikle ekleme horizontal stabilite özelliği kazandırmalıdır. Dolayısıyla anteriorda fonksiyonel ve sağlam bir subskapularise gereksinimi vardır. Subskapularis yırtık ise onarılabilir olmalıdır. Yine teres minörde ileri derecede yağlı dejenerasyon kötü sonuçla ilişkilendirilmektedir. ${ }^{[18]}$

Latissimus dorsi transferi için göreceli ve mutlak kontrendikasyonlar Tablo 1'de belirtilmiştir. ${ }^{[2,15]}$ 
Tablo 1. Latissimus dorsi transferi için kontrendikasyonlar ${ }^{[2,15]}$

\begin{tabular}{ll}
\hline Göreceli kontrendikasyonlar & Mutlak kontrendikasyonlar \\
\hline İleri yaş & Deltoid yetmezlik \\
Teres minörde ciddi yağlı dejenerasyon & ileri glenohumeral osteoartrit \\
Yüksek gerim altında subskapularis onarımı & Onarılamaz subskapularis yırtığı \\
Kötü kemik kalitesi & Enfeksiyon \\
Düşük hasta uyumu & Adduksiyonda komplet psödoparalizi \\
& Dinamik antero-superior kaçış sendromu
\end{tabular}

\section{Cerrahi Teknik}

Cerrahi için şezlong (beach-chair) ya da lateral dekübit pozisyonu kullanılabilir. Transfer işlemi açık ya da artroskopik destekli yapılabilir. Açık yöntem genel olarak Gerber'in tanımlamış olduğu double insizyon yöntemiyle yapılmaktadır. ${ }^{[18]} \mathrm{Her}$ iki teknikte de aksillanın posterior kenarından başlayıp latissimus dorsi lateral sınırından geçen ortalama 15 cm'lik curve (eğri) insizyon yapılır (Şekil 1). Latissimus dorsi kası posterodistalden bulunarak proksimale doğru diseke edilir. Proksimalde yassı tendinöz kısım teres majör üzerinden ayrılır (Şekil 2). Humerus anteromedialdeki insersiyosuna ulaştıktan sonra kol maksimum internal rotasyona çevrilerek mak-

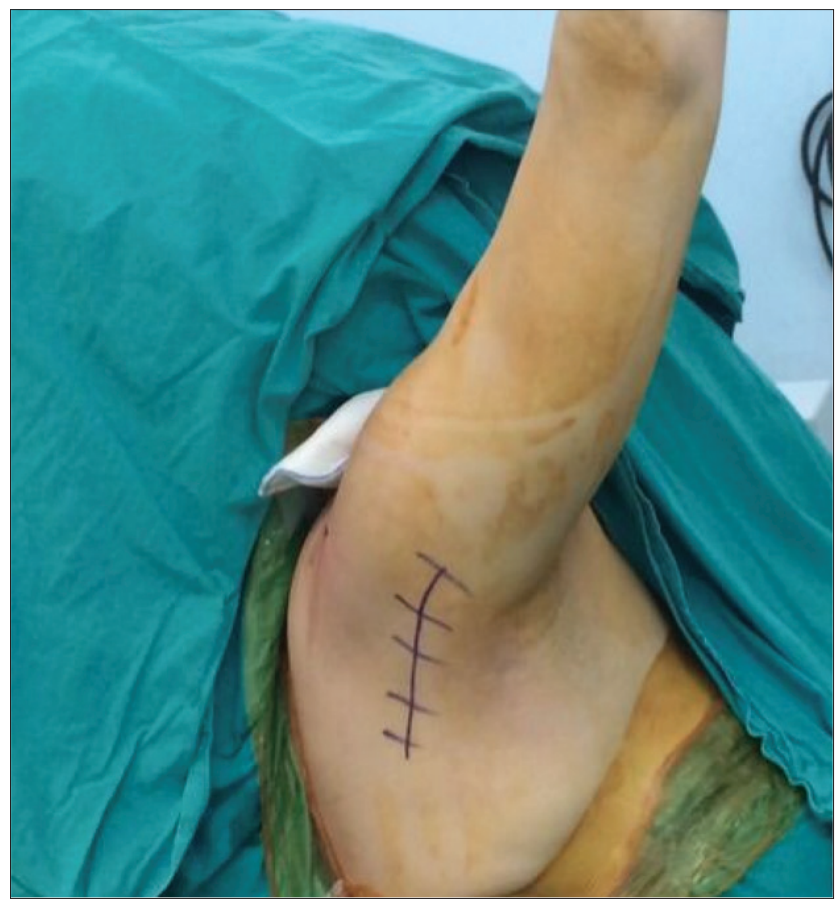

Şekil 1. Aksillanın posterior kenarından başlayıp latissimus dorsi lateral sınırından geçen ortalama $15 \mathrm{~cm}$ 'lik eğri (curve) insizyon hattı görülmektedir. simum tendon uzunluğuna ulaşılarak ve radial sinir korunarak insersiyosundan ayrılır. Latissimus dorsi tendonu insersiyosunda tendonun superiorunda ve humerusun medialinde radial sinir geçer. Yine teres majörün superior kenarında proksimalde aksiller sinir bulunur. Bu iki sinire bu aşamada dikkat etmek gerekir. Tendon proksimalden ayrıldıktan sonra kas distalde gögüs duvarına doğru diseke edilerek mobilizasyonu sağlanır. Bu aşamada kas gövdesine torakodorsal sinir pedikülünün girişi karşımıza çıkar ve pedikül aktif kas fonksiyonu açısından

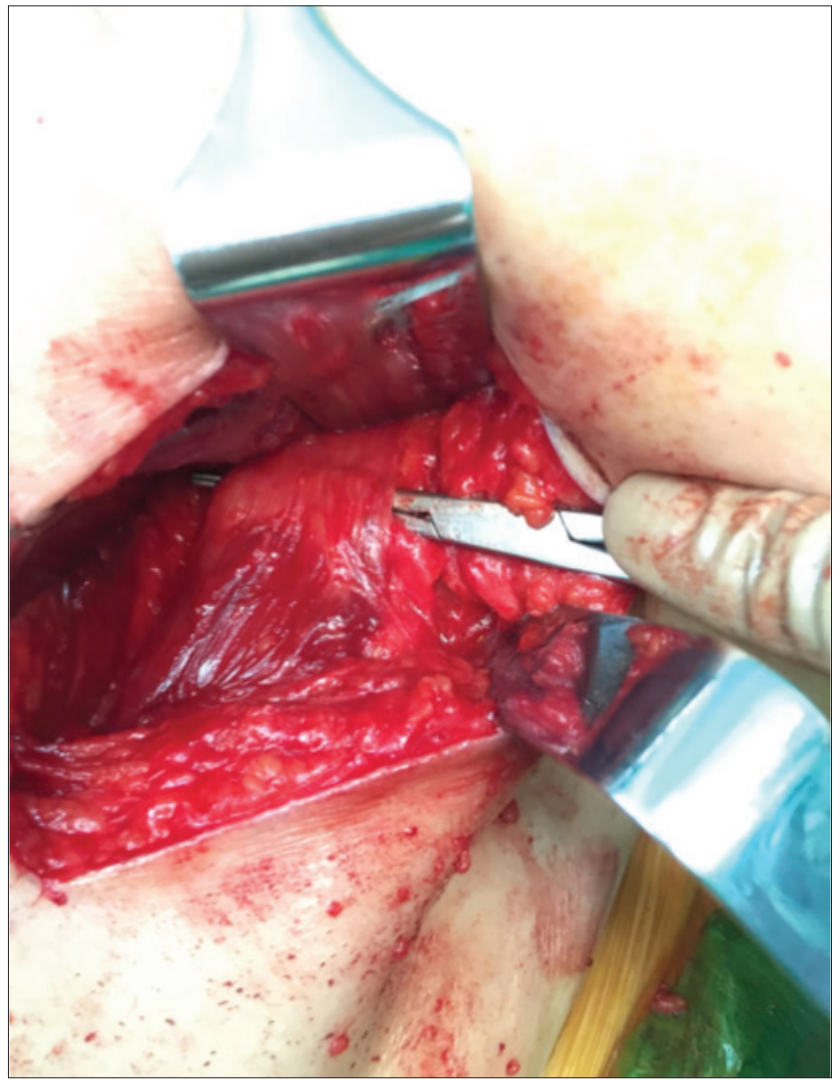

Şekil 2. Latissimus dorsinin yassı tendinöz kısmı teres majör üzerinden diseke edilir. 


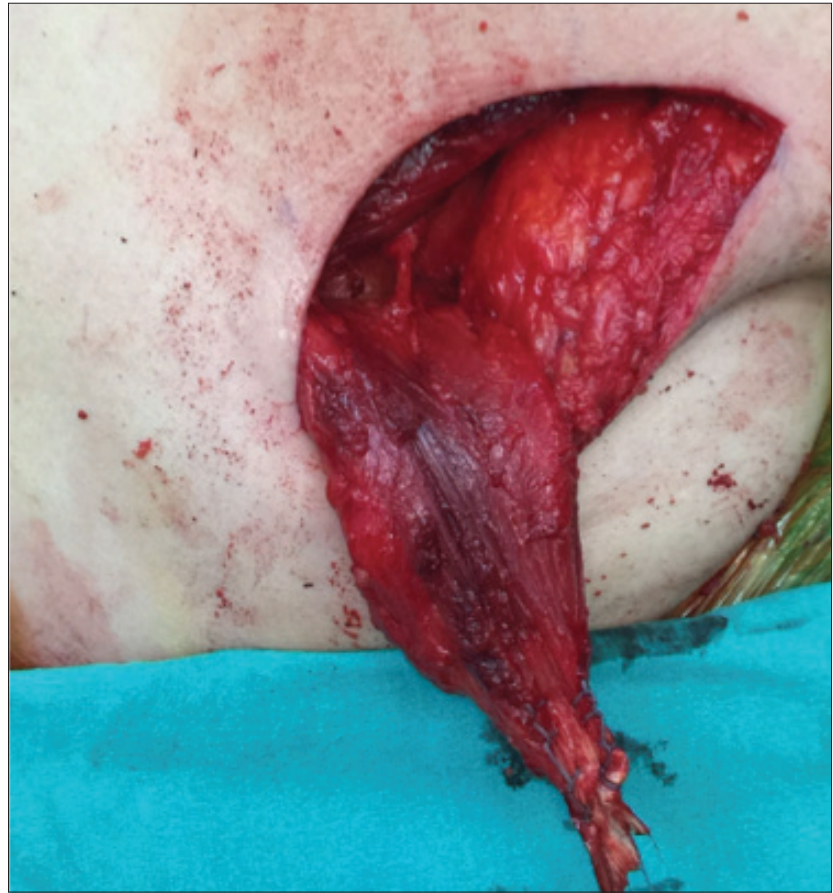

Şekil 3. Kol maksimum internal rotasyona çevrilerek maksimum tendon uzunluğuna ulaşılarak ve radial sinir korunarak insersiyosundan ayrilır.

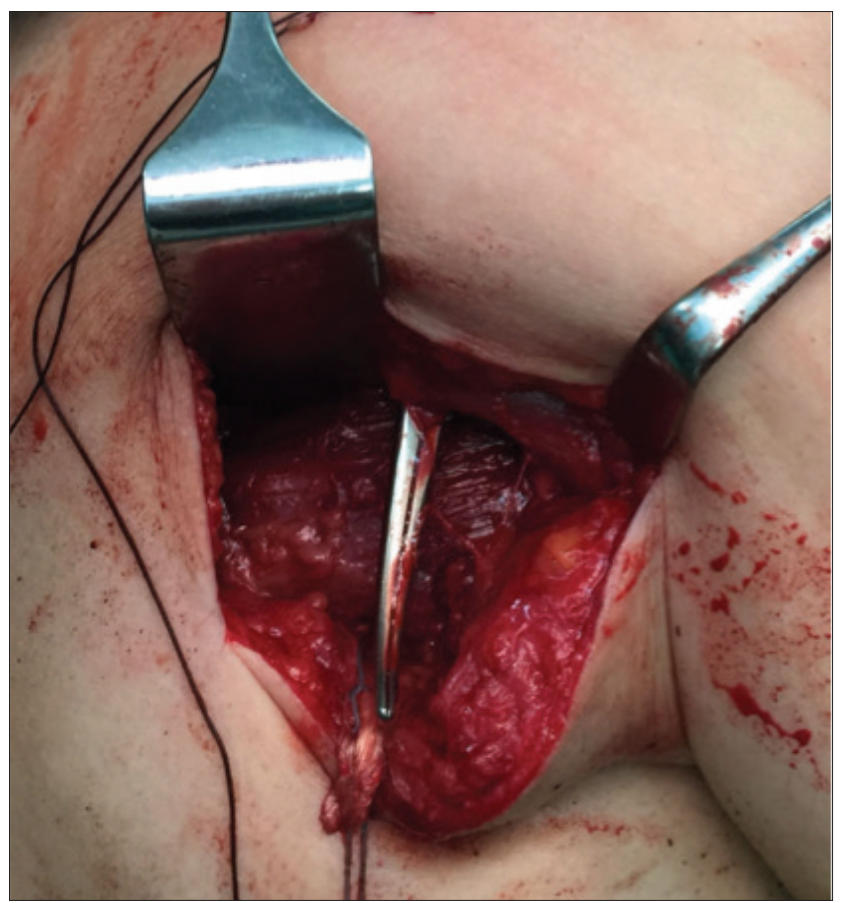

Sekil 4. Latissimus dorsi tendonu, teres minör ve deltoid arasındaki alandan subakromial aralığa çekilir.

korunmalıdır. Tendon Krackow sütür yöntemiyle örüldükten sonra teres minör ve deltoid arasındaki alandan subakromial aralığa çekilir (Şekil 3 ve 4). Artroskopik ${ }^{[22]}$

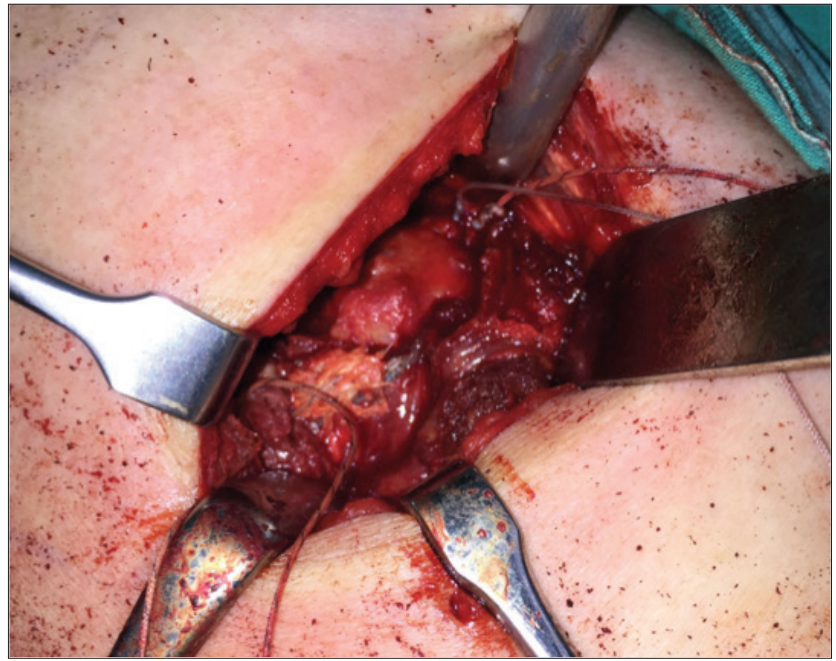

Şekil 5. Beklenen fonksiyona göre, tüberkulum majus lateraline, infraspinatus insersiyosuna ya da supraspinatus insersiyosuna tenodez işlemi yapılır.

ya da iki insizyonlu açık yöntemle tespit edilir. İki insizyon yöntemiyle açık tespit yapılacaksa anteriordan akromionun anterolateral köşesinden inferiora $5 \mathrm{~cm}$ 'lik insizyon yapılır. Deltoid anterior ve orta bölümleri arasından split olarak girilerek tüberkulum majus lateraline, infraspinatus insersiyonuna ya da supraspinatus insersiyosuna tenodez işlemi yapılır (Şekil 5).

Ameliyat sonrası üst ekstremite abduksiyon breysine alınır. Ilk altı hafta sadece pasif eklem hareketi verilir. Altı haftadan sonra breys sonlandırılarak aktif harekete başlanır ve 12 haftadan sonra aşamalı olarak direnç egzersizlerine geçilir.

Postero-superior onarılamayan manşet yırtıklarında yapılan latissimus dorsi transferiyle ilgili yapılan çalışmalardan Gerber'in uzun dönem takipli çalışması literatürde önemli bir yere sahiptir. ${ }^{[23]}$ Latissimus dorsi transferi sonrası subjektif omuz skoru ameliyat öncesi \%29'dan ameliyat sonrası \%70'e, Constant skoru ameliyat öncesi \%56'dan \%80'e ve ağrı skoru ameliyat öncesi yedi puandan ameliyat sonrası 13 puana, ortalama fleksiyon $118^{\circ}$ 'den $132^{\circ}$ 'ye, abduksiyon $112^{\circ}$ 'den $123^{\circ}$ 'ye ve eksternal rotasyonu ise $18^{\circ}$ 'den $33^{\circ}$ ye yükseldiği belirtilmiştir. Kötü sonuçların subskapularis yetmezliği ve teres minördeki yağlı dejenerasyonla ilişkili olduğunu öne sürmüştür. Costouros ise çalışmasında teres minor yırtık olmasa bile eğer stage 2'nin üstünde yağlı dejenerasyon varsa daha düşük Constant skoru elde ettiklerini bildirmişlerdir. ${ }^{[24]}$

Artroskopi destekli latissimus dorsi transferi ile açık yöntem karşılaştırıldığında; artroskopik destekli yöntemle ilgili uzun dönem yeterli sayıda çalıșma olmamasına rağmen gerek klinik sonuçlar gerekse komplikasyonlar açısından oldukça memnuniyet vericidir. ${ }^{[25]}$ 
Ameliyat öncesi kötü omuz fonksiyonuna sahip kadın hasta ve kas güçsüzlüğü, kötü klinik sonuç için daha büyük risk taşımaktadır. Ameliyat öncesi dönemde osteoartritin olması ve ameliyat sonrası osteoartritin ilerlemesi kötü fonksiyonel sonuçla ilişkilidir. Literatürdeki çalışmalar ışığında latissimus dorsi transferi için en uygun aday, genç, deltoid aktif, teres minörü ve subskapularisi sağlam, daha önce rotator manşet onarımı yapılmamış, aktif eksternal rotasyonu mevcut ve ağrılı elevasyon kaybı olan hastalardır. Yaşlı, aksiller siniri sağlam olmasına rağmen deltoidin aktif, psödoparalizi olan olgularda, glenohumeral dejenerasyon olmasa bile biyomekanik olarak en iyi seçenek reverse omuz protezidir. ${ }^{[26]}$

\section{ALT TRAPEZIUS TENDON TRANSFERI}

Tarihsel açıdan baktığımızda trapezius kası erişkin brakial pleksus yaralanmalarında en sık kullanılmış tendon transferidir. ${ }^{[27]}$ ilk olarak Elhassan ve ark. brakial pleksus yaralanmalı hastalarda omuz eksternal rotasyonunu restore etmek için alt ve orta trapezius transferi uygulamışlardır. Daha sonra yine Elhassan ve ark. bu tekniği onarılamayan postero-superior rotator manşet yaralanmalarında kullanmaya başlamışlardır. ${ }^{[28]}$

Latissimus dorsi transferi ile karşılaştırıldığında, alt trapezius, infraspinatusun vektörel yönüne daha yakındır. En ideal endikasyonu eksternal rotasyonun izole kaybıdır. Bu durumda latissimus dorsi transferine göre sonuçları daha iyidir. ${ }^{[14]}$ Tendinöz kısmı çok kısa olduğu için allogreft ile kombine edilip uzatılarak humerus footprintine ulaştırılır (Şekil 6). Transfer infraspinatus üst bölümü ile supraspinatus footprintine yapılır. İnnervasyonunu sağlayan ve skapulanın $2 \mathrm{~cm}$ medialinden geçen spinal aksesuar sinir korunmalıdır. Kol $0^{\circ}$ 'de gövde yanındayken aktif eksternal rotasyon kayıpları için özellikle etkilidir. Bu transferin önemli bir problemi serratus anterior fonksiyonunda bir yetersizlik varsa skapula üzerindeki stabilize edici etki kalkacağı için kanat skapulaya neden olabilir.

Elhassan ve ark.'nın yaptığı çalışmada, ameliyat öncesi aktif öne fleksiyon derecesi $60^{\circ}$ 'nin üzerinde olan 33 hastanın 32'sinde alt trapezius transferiyle 47 ay takip sonrası ağrıda gerileme olduğunu, ortalama aktif abduksiyon $90^{\circ}$, fleksiyon $120^{\circ}$ ve eksternal rotasyon $50^{\circ}$ 'ye yükseldiğini göstermişlerdir. ${ }^{[28]}$ Hartzler ve ark.'nın yaptığı biyomekanik modelleme çalışmasında LD, teres majör ve alt trapezius transferlerini değerlendirmişlerdir. Buna göre, adduksiyondaki omuzda alt trapezius en geniş eksternal rotasyon moment koluna sahip olduğu ve LD'nin ise en düşük eksternal rotasyon moment koluna sahip olduğunu göstermişlerdir. Latissimus dorsi transferi potansiyel olarak $90^{\circ}$ abduksiyondaki omuzda en

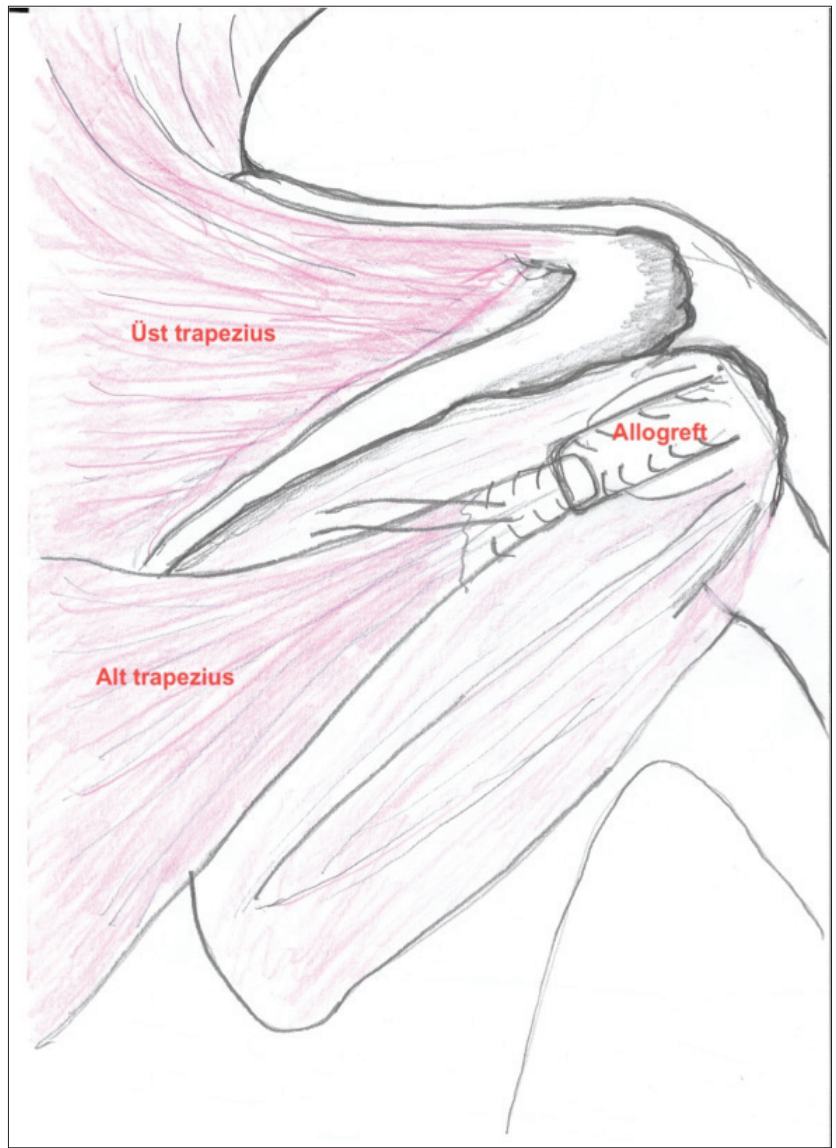

Şekil 6. Alt trapezius transferi: Tendinöz kısmı çok kısa olduğu için semitendinöz ya da aşil allogrefti ile kombine edilir.

etkin eksternal rotasyon yapıcı role sahip olarak değerlendirilmiştir. ${ }^{[20]}$ Omid ve ark.'nın yapmış olduğu diğer bir biyomekanik çalışmada doğal glenohumeral biyomekaniğini ve eklem reaksiyon güçlerini restore etmede alt trapeziusun LD transferine göre daha üstün olduğunu belirtmişlerdir. ${ }^{[21]}$

\section{TERES MAJÖR TENDON TRANSFERI}

İole olarak transferine nadir gereksinimi olan ve aynı zamanda literatürde kullanım yeri yeteri kadar netlik kazanamamış bir transfer tekniğidir. Bu transfer sadece infraspinatus yetmezliğinde kullanılır ve supraspinatusun sağlam olması gerekir. ${ }^{[29]}$ Eğer supraspinatus da onarılamayacak özellikte ise alt trapezius ya da LD transferlerinin eklenmesi önerilir. Mansat ve arkadaşlarının 12 hastadan oluşan çalışmalarında altı yıllık izlem sonunda omuz fonksiyonel skorlarda ve ağrı skorunda iyileşme tespit etmişlerdir. Bu transfer için en uygun olguların teres minörün, anterior supraspinatus kablonun ve subskapularisin sağlam olduğu 55 yaş altı hastalar olduğunu belirtmişlerdir. ${ }^{[30]}$ 


\section{TERES MAJÖR + LATISSIMUS DORSI TRANSFERI (L'EPISCOPO PROSEDÜRÜ)}

Illk olarak 1934 yılında L'Episcopo tarafından, obstetrik brakial pleksus palside teres majör ve latissimus dorsi birlikte transferi tanımlanmıştır. ${ }^{[3]]}$ Bu teknik daha sonra onarılamayan postero-superior manşet yetmezliklerinde eksternal rotasyon kaybını restore etmek üzere 2002 yılında Habermeyer tarafından modifiye edilmiştir. ${ }^{[32]}$ Boileau ve ark., reverse omuz protezli uygulamalarında modifiye tek insizyon (deltopektoral) yöntemiyle teres majörle birlikte LD transferinin daha fazla eksternal rotasyon sağladığını belirtmiştir. ${ }^{[33]}$

\section{ONARILAMAYAN ANTERO-SUPERIOR ROTATOR MANŞET YIRTIKLARI}

Temel onarılamayan manşet unsuru subskapularistir. Postero-superior yetmezliklere göre daha az görülür. Subskapularis yırtıkları izole görülmekten çok supraspinatus yırtığı ile birlikte görülür. ${ }^{[34]}$

Omuzdaki temel fonksiyonu primer internal rotasyon (IR) ve anterior dinamik stabilizasyondur. ${ }^{[35]}$ Yetmezliğinde, klinik olarak belly- press, bear hug, ve liftoff testleri ile değerlendirilir. ${ }^{[36-38]}$ Kronik yırtıklar zamanla Goutallier grade 3 ve üstü yağlı dejenerasyona neden olabilir. Hem anterior stabilizasyonda hem de îR gücünde azalmaya neden olur. ${ }^{[25,39]}$

Temel olarak, pektoralis majör, pektoralis minör ve latissimus dorsi transferleri kullanılır.

\section{PEKTORALIS MAJÖR TENDON TRANSFERI}

Bu transferin amacı, subskapularis (SSk) yetmezliğine bağı ıelişen internal rotasyon kaybını düzeltmektir. SSk, primer internal rotator ve dinamik anterior stabilizatördür. SSk yetmezliğinde anterior omuz ağrısı ve aktif îR kaybı gelişir. Fizik muayenede pozitif belly-press, bearhug ve lift-off testi görülür. ${ }^{[36,37]}$ Yine MRI'da Goutallier 3 ve üzerinde yağlı dejenerasyon varsa onarım sonuçları kötüdür. ${ }^{[13]}$ Bu durumda da pektoralis majör (PMa) tendon transferi IR güçlerini restore etmek için önemlidir. Temel olarak PMa humerus üzerinde adduksiyon, iR ve fleksiyon güçleri oluşturur. PMa tendon transferi için 65 yaş altı, fonksiyonel bir deltoid, minimal glenohumeral artrit, sağlam ya da onarılabilir postero-superior rotator manşet kriterlerinin olması gerekmektedir. ${ }^{[39]}$

Pektoralis majör transferi ilk olarak 1997'de Wirth tarafından tanımlanmıştır. ${ }^{[14]}$ Subskapularis yetmezliğinde PMa'nın tamamını konjoint tendon üzerinden, anteriorundan geçirerek transfer işlemi uygulamıştır. Beş yıllık izlemde yüksek başarı oranı bildirmiştir. Daha sonra

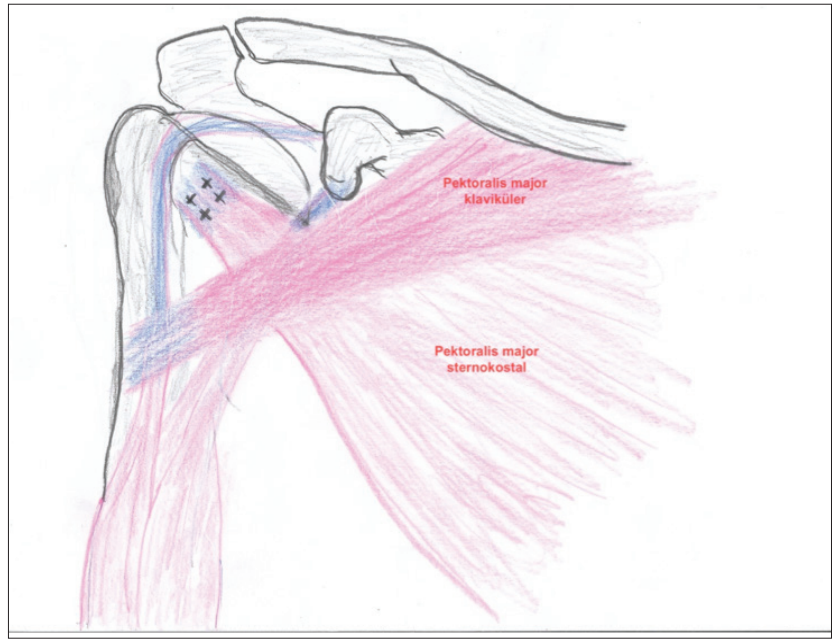

Şekil 7. Pektoralis majör transferi.

bu yöntem Resch ve ark. tarafından modifiye edilerek PMa'nın üst 2/3'lük bölümünü konjoint tendon altından, arkasından geçirerek transfer işlemi uygulamaya başlamışlardır. Her ne kadar bu modifiye yöntemde muskulokütanöz sinir riski daha yüksek olsa da, biyomekanik olarak daha üstündür. ${ }^{[39]}$

Cerrahi işlem lateral dekübit ya da beach-chair pozisyonunda uygulanabilir. Uzun deltopektoral insizyon uygulanır. Bu şekilde inferiorda PMa'nın iki başı (klaviküler ve sternokostal) lokalize edilir. Total transfer kozmetik nedenler ile önerilmemektedir. Bunun yerine superiordaki bölümü olan klaviküler segment ile beraber sternokostal segmentin bir bölümü ya da inferior sternal başın tek başına (Wagner) transferi uygulanmaktadır (Şekil 7). Bu teknikleri karşılaştıran çalışmalar yeterli sayıda olmamasına rağmen sonuçlar arasında anlamlı bir fark tespit edilmemiştir. Klinik sonuçlar ile ilgili literatürde yeterli çalışma olmamasına rağmen Resch ve daha sonra Galatz'ın yaptığı çalışmaların sonuçlarına göre ağrı ve fonksiyonel skorlarda önemli oranda gelişme kaydetmişlerdir. ${ }^{[38,40]}$

\section{PEKTORALIS MINÖR TENDON TRANSFERI}

Pektoralis minör (PMi) tendon transferi ilk olarak Wirth tarafından tanımlanmıştır. Paladini tarafından modifiye edilmiştir. ${ }^{[1,41]}$ Korakoid apofizin medialinden bir kemik blok ile alınıp konjoint tendonun arkasından tüberkulum minus üst $2 / 3$ 'lük bölümüne tespit etmiştir. İki yıl izlemli 27 hastalık serisinde Constant skorlarında düzelme ve \%78'inde günlük aktiviteye geri dönüş bildirmiştir. ${ }^{[41]}$

İdeal traksiyon çizgisine sahip olmadığı için yeterli internal rotasyon gücü oluşturamaz. Hatta eksternal rotasyon kısıtlılığına neden olabilmektedir. ${ }^{[14]}$ 


\section{LATISSIMUS DORSI TRANSFERI}

Postero-superior manşet yetmezliklerinde kullanılmakla beraber antero-superior manşet yetmezliklerinde subskapularis disfonksiyonunda da kullanılan bir transfer yöntemidir. ${ }^{[42,43]}$

$\mathrm{Bu}$ transferde standart deltopektoral yaklaşım kullanılır. Tüm hastalarda standart biseps tenodezi ya da tenotomisi uygulanır. Aksiller ve muskulokütanöz sinirler korunur. Tüberkulum minus ortaya konur. Pektoralis majör tendonunun humerusa yapışma yerinin üst $1 / 3$ 'ü kaldırılır. Bu aralıktan girilerek latissimus dorsi tendonunun humerustaki insersiyosuna ulaşılır. Teres majördan diseke ederek ayrılır. Üst ekstremite $0-30^{\circ}$ eksternal rotasyon aralığındayken tendon tüberkulum minusa transfer edilir.

Elhassan çalışmasında onarılamayan subskapularis hasarlarında LD transferinin uygun bir yöntem olduğunu ve sinir sıkışması açısından bir risk taşımadığını belirtmiştir. ${ }^{[42]}$ Mun ve ark.'nın çalışmasında LD transferinin pektoralis majör transferine göre; gerek fonksiyon gerekse yönelim açısından subskapularis kasına daha yakın olduğunu belirtmişlerdir. ${ }^{[43]}$ Literatürde bu iki transferi karşılaştıran çalışma sayısı çok azdır.

Onarılamayan rotator manşet yaralanmalarında tendon transferleri uzun yıllardır yaygın olarak kullanılmaktadır. Özellikle postero-superior manşet yetmezliklerinde son yıllarda latissimus dorsi ve alt trapezius transferi ile ilgili oldukça umut verici çalışmalar mevcuttur. Latissimus dorsi tendon transferinin hem postero-superior hem de antero-superior yetmezlikte kullanılabilmesi önemli bir özelliktir. İzole aktif fonksiyonun olduğu, psödoparalizinin olmadığı, genç ve aktif hastalarda fonksiyonel kazanım için iyi bir seçenektir.

\section{KAYNAKLAR}

1. Neri BR, Chan KW, Kwon YW. Management of massive and irreparable rotator cuff tears. J Shoulder Elbow Surg 2009;18(5):808-18. Crossref

2. Oh JH, Park MS, Rhee SM. Treatment Strategy for Irreparable Rotator Cuff Tears. Clin Orthop Surg 2018;10(2):119-34. Crossref

3. Dines DM, Moynihan DP, Dines J, McCann P. Irreparable rotator cuff tears: what to do and when to do it; the surgeon's dilemma. J Bone Joint Surg Am 2006;88(10):2294-302. Crossref

4. Merolla G, Chillemi C, Franceschini V, Cerciello S, Ippolito G. et al. Tendon transfer for irreparable rotator cuff tears: indications and surgical rationale. Muscles Ligaments Tendons J 2015;4:425-432. Crossref

5. Rockwood CA, Williams GR, Burkhead WZ. Débridement of degenerative, irreparable lesions of the rotator cuff. J Bone Joint Surg Am 1995;77(6):857-66. Crossref
6. Burks RT,Tashjian RZ. Should we have a better definition of pseudoparalysis in patients with rotator cuff tears? Arthroscopy 2017;33:2281-3 Crossref

7. Fuchs B, Weishaupt D, Zanetti M, Hodler J, Gerber C. Fatty degeneration of the muscles of the rotator cuff: assessment by computed tomography versus magnetic resonance imaging. J Shoulder Elbow Surg 1999;8:599-605. Crossref

8. Goutallier D, Postel Jm, Bernageau J, lavau I, Voisin MC. Fatty infiltration of disrupted rotator cuff muscles. Rev Rhum Engl Ed 1995;62:415-22.

9. Omid R, Lee B. Tendon transfers for irreparable rotator cuff tears. A Am Acad Orthop Surg 2013;21:492-501. Crossref

10. Patte D. Classification of rotator cuff lesions. Clin Orthop Relat Res 1990;254:81-6. Crossref

11. Thomazeau h, Rolland Y, Lucas C, Duval JM, langlais F. Atrophy of the supraspinatus belly. Assessment by MRI in 55 patients with rotator cuff pathology. Acta Orthop Scand 1996;67:264-8. Crossref

12. Hoffer MM, Wickenden R, Roper B. Brachial plexus birth palsies. Results of tendon transfers to the rotator cuff. J Bone Joint Surg Am 1978;60:691-695. Crossref

13. Elhassan BT, Alentorn Geli E, Assenmacher AT, Wagner ER. Arthroscopic- assisted lower trapezius tendon transfer for massive irreparable posterior- superior rotator cuff tears: surgical technique. Arthrosc Tech 2016;5:981-988. Crossref

14. Wirth MA, Rockwood Jr CA. Operative treatment of irreparable rupture of the subscapularis. J Bone Joint Surg Am 1997;79:722-731. Crossref

15. KanyJ. Tendon transfers in rotator cuff surgery. Orthop Traumatol Surg Res 2020 ;106(1S):43-51. Crossref

16. Boileau P, McClelland WBJ, Rumian AP. Massive irreparable rotator cuff tears: how to rebalance the cuff deficient shoulder. Instr Course Lect 2014;63:71-83.

17. Bartlett SP, May JW Jr, Yaremchuk MJ. The Latissimus Dorsi muscle: a fresh cadaver study of the primary neurovascular pedicle. Plast Reconstr Surg 1981;67(5):631-6. Crossref

18. Gerber C, Vinh TS, Hertel R, Hess CW. Latissimus Dorsi transfer for the treatment of massive tears of the rotator cuff. A preliminary report. Clin Orthop Relat Res1988;(232):51-61. Crossref

19. Oh JH, Tilan J, Chen YJ, Chung KC, McGarry MH, Lee TQ. Biomechanical effect of Latissimus Dorsi tendon transfer for irreparable massive cuff tear. J Shoulder Elbow Surg 2013;22(2):150-7. Crossref

20. Hartzler RU, Barlow JD, An KN, Elhassan BT. Biomechanical effectiveness of different types of tendon transfers to the shoulder for external rotation. J Shoulder Elbow Surg 2012;21:1370-6. Crossref

21. Omid R, Heckmann N, Wang L, McGarry MH, Vangsness CT, Lee TQ. Biomechanical comparison between the trapezius transfer and latissimus transfer for irreparable postero-superior rotator cuff tears. J Shoulder Elbow Surg 2015;24(10):1635-43. Crossref 
22. Gervasi E, Causero A, Parodi PC, Raimondo D, Tancredi G. Arthroscopic Latissimus Dorsi transfer. Arthroscopy2007;23(11):1243. Crossref

23. Gerber C, Rahm SA, Catanzaro S, Farshad M, Moor BK. Latissimus Dorsi tendon transfer for treatment of irreparable postero-superior rotator cuff tears: long-term results at a minimum follow-up of ten years. J Bone Joint Surg Am) 2013;95(21):1920-1926. Crossref

24. Costouros JG, Espinosa N, Schmid MR, Gerber C.Teres minor integrity predicts outcome of Latissimus Dorsi tendon transfer for irreparable rotator cuff tears. J Shoulder Elbow Surg 2007;16(6):727-34. Crossref

25. Memon M, Kay J, Quick E, Simunovic N, Duong A, Henry P, et al. Arthroscopic-assisted Latissimus Dorsi tendon transfer for massive rotator cuff tears: a systematic review. Orthop. J. Sports Med 2018;6(6):2325967118777735. Crossref

26. Iannotti JP, Hennigan S, Herzog R, Kella S, Kelley M, Leggin $B$, et al. Latissimus Dorsi tendon transfer for irreparable postero-superior rotator cuff tears. Factors affecting outcome. J Bone Joint Surg Am2006;88(2):342-8. Crossref

27. Karev A. Trapezius transfer for paralysis of the deltoid. J Hand Surg Br 1986;11(1):81-3. Crossref

28. Elhassan BT, Wagner ER, Werthel JD. Outcome of lower trapezius transfer to reconstruct massive irreparable posterior-superior rotator cuff tear. J Shoulder Elbow Surg 2016;25(8):1346-53. Crossref

29. Celli A, marongiumC, Rovesta C, Celli I. Transplant of the teres major in the treatment of irreparable injuries of the rotator cuff (long-term analysis of results). Chir Organi Mov 2005;90:121-32. Crossref

30. Mansat P, Dotziz A, Bellumore Y, Mansat M. Teres major flap: surgical anatomy, technique of harvesting, methods of fixation, postoperative management. In: Valenti P. (ed.) Tendon Transfer For Irreparable Rotator Cuff Tear. Paris: SpringerVerlag France, 2011; p. 49-64. Crossref

31. L'Episcopo JB. Tendon transplantation in obstetrical paralysis. Am J Surg 1934;25(1):122-5. Crossref

32. Habermeyer $\mathrm{P}$, Magosch $\mathrm{P}$, Lichtenberg $\mathrm{S}$. The modified L'Episcopo procedure to reconstruct massive rotator cuff tears --a prospective study. In: Annual Meeting of the American Academy of Orthopaedic Surgeons; , Dallas, TX. 2002; p. 13-7.
33. Boileau P,Chuinard C, Roussanne Y, Neyton L, Trojani C. Modified Latissimus Dorsi and teres major transfer through a single delto-pectoral approach for external rotation deficit of the shoulder: as an isolated procedure or with a reverse arthroplasty. J Shoulder Elbow Surg 2007;16(6):671-82. Crossref

34. lyonsr P, Green A. Subscapularis tendon tears. J Am Acad Orthop Surg 2005;13: 353-63. Crossref

35. Axe JM.Tendon transfers for irreparable rotator cuff tears: An update. EFORT Open Rev 2017 13;1(1):18-24. Crossref

36. Burkhart SS, Tehrany AM. Arthroscopic subscapularis tendon repair: technique and preliminary results. Arthroscopy 2002;18:454-63. Crossref

37. Barth Jr, Burkhart SS, de Beer JF. The bear-hug test: a new and sensitive test for diagnosing a subscapularis tear. Arthroscopy 2006;22:1076-84. Crossref

38. Resch H, Povacz P, Ritter E, Matschi W. Transfer of the pectoralis major muscle for the treatment of irreparable rupture of the subscapularis tendon. J Bone Joint Surg Am 2000;82-A:372-82. Crossref

39. Nelson GN, Namdari S, Galatz L, Keener JD. Pectoralis major tendon transfer for irreparable subscapularis tears. J Shoulder Elbow Surg 2014;23:909-18. Crossref

40. Galatz LM, Connor PM, Calfee RP, Hsu JC, Yamaguchi K. Pectoralis major transfer for anterior-superior subluxation in massive rotator cuff insufficiency. J Shoulder Elbow Surg 2003;12(1):1-5. Crossref

41. Paladini P, Campi F, Merolla G, Pellegrini A, Porcellini G. Pectoralis minor tendon transfer for irreparable antero-superior cuff tears. J Shoulder Elbow Surg 2013;22(6):e1-e5. Crossref

42. Elhassan B, Christensen TJ, Wagner ER. Feasibility of latissimus and teres major transfer to reconstruct irreparable subscapularis tendon tear: an anatomic study. J Shoulder Elbow Surg 2013;27:1-8.

43. Mun SW, Kim JY, Yi SH, Baek CH. Latissimus Dorsi transfer for irreparable sub-scapularis tendon tears. J Shoulder and Elbow Surg 2018;27:1057-1064. Crossref 